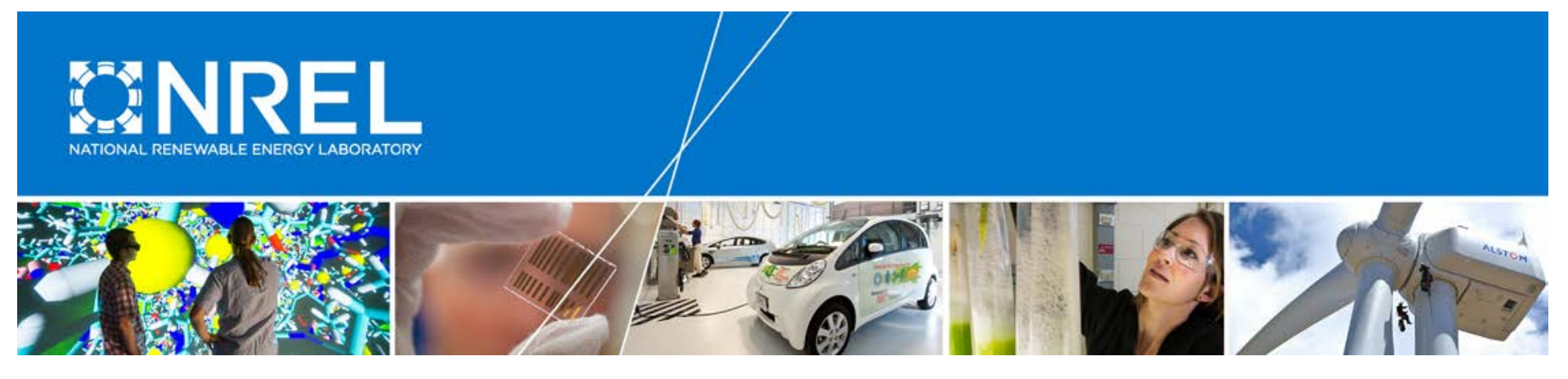

\title{
Analysis of a Single Year of Performance Data for Thin Film Modules Deployed at NREL and NISE
}

Sara MacAlpine, Michael Deceglie, and Sarah Kurtz

National Renewable Energy Laboratory

Birinchi Bora, O.S. Sastry, Yogesh Kumar Singh, Rashmi Singh, and Supriya Rai National Institute of Solar Energy

NREL is a national laboratory of the U.S. Department of Energy Office of Energy Efficiency \& Renewable Energy Operated by the Alliance for Sustainable Energy, LLC

This report is available at no cost from the National Renewable Energy Laboratory (NREL) at www.nrel.gov/publications.

Technical Report

NREL/TP-5J00-66963

August 2016

Contract No. DE-AC36-08GO28308 


\section{Analysis of a Single Year of Performance Data for Thin Film Modules Deployed at NREL and NISE}

Sara MacAlpine, Michael Deceglie, and Sarah Kurtz

National Renewable Energy Laboratory

Birinchi Bora, O.S. Sastry, Yogesh Kumar Singh, Rashmi Singh, and Supriya Rai National Institute of Solar Energy

Prepared under Task No. IGIN1102

NREL is a national laboratory of the U.S. Department of Energy Office of Energy Efficiency \& Renewable Energy Operated by the Alliance for Sustainable Energy, LLC

This report is available at no cost from the National Renewable Energy Laboratory (NREL) at www.nrel.gov/publications.

National Renewable Energy Laboratory 15013 Denver West Parkway Golden, CO 80401

303-275-3000 • www.nrel.gov
Technical Report

NREL/TP-5J00-66963

August 2016

Contract No. DE-AC36-08G028308 


\section{NOTICE}

This report was prepared as an account of work sponsored by an agency of the United States government. Neither the United States government nor any agency thereof, nor any of their employees, makes any warranty, express or implied, or assumes any legal liability or responsibility for the accuracy, completeness, or usefulness of any information, apparatus, product, or process disclosed, or represents that its use would not infringe privately owned rights. Reference herein to any specific commercial product, process, or service by trade name, trademark, manufacturer, or otherwise does not necessarily constitute or imply its endorsement, recommendation, or favoring by the United States government or any agency thereof. The views and opinions of authors expressed herein do not necessarily state or reflect those of the United States government or any agency thereof.

This report is available at no cost from the National Renewable Energy Laboratory (NREL) at www.nrel.gov/publications.

Available electronically at SciTech Connect http:/www.osti.gov/scitech

Available for a processing fee to U.S. Department of Energy and its contractors, in paper, from:

U.S. Department of Energy

Office of Scientific and Technical Information

P.O. Box 62

Oak Ridge, TN 37831-0062

OSTI http://www.osti.gov

Phone: 865.576.8401

Fax: 865.576.5728

Email: reports@osti.gov

Available for sale to the public, in paper, from:

U.S. Department of Commerce

National Technical Information Service

5301 Shawnee Road

Alexandria, VA 22312

NTIS http://www.ntis.gov

Phone: 800.553 .6847 or 703.605 .6000

Fax: 703.605.6900

Email: orders@ntis.gov 


\section{Introduction}

The National Renewable Energy Laboratory (NREL) and National Institute of Solar Energy (NISE), located in the United States and India, respectively, have partnered to deploy and monitor modules of three different thin film technologies, to compare the performance and/or degradation between the two sites. The modules, shown in Figure 1, are deployed at a fixed latitude tilt at NREL, and on a manual dual axis tracker at NISE. At each site there are two modules each of CIGS, CdTe, and Micromorph (amorphous and microcrystalline silicon) technologies. The modules are listed in Table 1; all were purchased new from their manufacturers in 2012 and 2013.
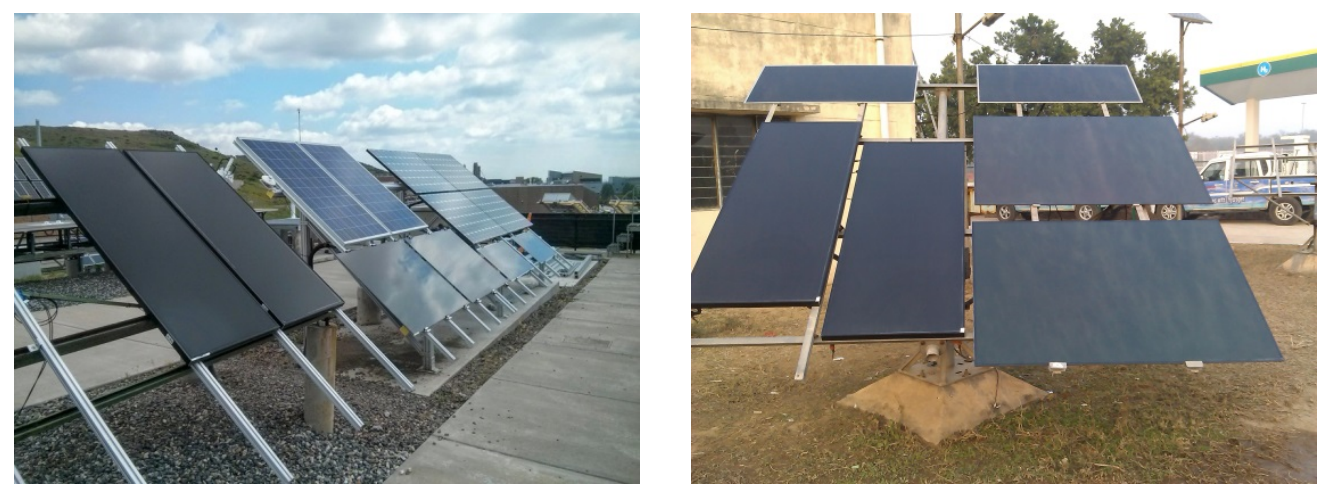

Figure 1. Thin film modules deployed at NREL (left) and NISE (right)

Table 1. Thin Film Module Details

\begin{tabular}{cccc} 
Module & Rated Power & \multicolumn{2}{c}{ Identifier } \\
\cline { 3 - 4 } Technology & (W) & NREL & NISE \\
\hline \hline CIGS & 125 & CIGS26 & CIGS798 \\
CIGS & 125 & CIGS27 & CIGS803 \\
CdTe & 80 & CdTe30 & CdTe210 \\
CdTe & 80 & CdTe31 & CdTe437 \\
Micromorph & 125 & Micro28 & Micro939 \\
Micromorph & 130 & Micro29 & Micro209
\end{tabular}

Prior to recording baseline I-V curves at NREL and NISE, the CIGS and CdTe modules were preconditioned using techniques that are recommended for these technologies. The micromorph modules were not preconditioned. STC power ratings for each module after preconditioning, as found using indoor flash testing, and during outdoor deployment, are listed in Table 2.

Plane-of-array irradiance and module temperature, as well as the module level DC I-V curves, were then recorded for over a year at each site, starting in November, 2013 at NREL and December, 2013 at NISE. Operating conditions and module level I-V curves were recorded continuously during daylight hours, every 5 minutes at NREL, while NISE employed a portable I-V curve tracer that was rotated between the systems on a regular basis. While not connected to the curve tracer, modules at NISE were kept under resistive load; this practice commenced in October, 2014. Irradiance at NISE was measured using a monocrystalline reference cell and module temperature was measured with an RTD element that is part of the I-V curve tracer. NREL's irradiance was measured using a thermopile pyranometer and each module's temperature measurements came from a designated film thermocouple.

This report includes three sections, analyzing a single year of performance data (May 2014 - April/May 2015) for the three thin film technologies. In the first section, the modules' observed performance is compared on a monthly basis, as well as to the datasheet values under standard test conditions (STC - 
$1000 \mathrm{~W} / \mathrm{m}^{2}$ and $25^{\circ} \mathrm{C}$ ). Most modules are found to slightly underperform their STC rated power, with a variation of approximately $2-10 \%$ over the year. This observation is further explored in the second section, where module fill factors at NREL are presented varying season, light level, and temperature. The third section documents each module's performance ratio, quantifying the effect of temperature for the three different thin film technologies relative to both the name plate and measured module ratings. Of the modules in this study, we see that the CdTe modules perform similarly and consistently at both the NREL and NISE sites, while micromorph performs better during the warmer summertime months at NREL and CIGS performs better during the rainy winter months at NISE.

\section{Module Performance Metrics}

\section{Standard Test Conditions (STC)}

Figure 2 shows the outdoor monthly STC power ratings for each of the thin film modules, normalized to their nameplate rating. There are no data for October, 2014 at NISE due to a system malfunction. The power ratings are calculated as follows, for each month:

- Filter data by irradiance - 950-1050 W/m² (NREL) and 800-1050 W/m² (NISE). A stability filter is applied to make sure that the irradiance is not changing by more than $2 \%$ between 5 minute I-V curve trace intervals at NREL; this step was not necessary at NISE because data were taken only under stable conditions.

- Scale the maximum power $\left(\mathrm{P}_{\mathrm{mp}}\right)$ to $1000 \mathrm{~W} / \mathrm{m}^{2}$, linear-by-irradiance.

- Filter module temperatures below $25^{\circ} \mathrm{C}$ and then outliers (points outside of an initial linear least squares fit of all of the remaining power vs. temperature data, $+/-2 \%$ ).

- Use datasheet temperature coefficients for each module to scale each power measurement to $25^{\circ} \mathrm{C}$.

- Calculate the mean STC power.

There are several interesting things to note from Figure 2. With regard to the CdTe modules, one can see that CdTe31 exhibits a decline in performance starting in or around January, 2015. Visual inspection of the module shows a crack, which may have been a result of a nick to the edge of the module. The crack may account for the decline in performance. Module CdTe437 at NISE also shows a decline in performance starting in April, 2015, but has no visible defects. The CIGS modules at both sites show seasonal variation; the power rating for all four modules increases by $5-10 \%$ in the winter months, possibly due to spectral effects or seasonal annealing. While the CIGS modules at NISE show similar performance to one another over the year, at NREL CIGS27 clearly underperforms CIGS26 each month. Though the two modules have the same datasheet rated power, NREL's pre-deployment I-V curve reports show that CIGS26 has always performed slightly better than CIGS27 (Table 2), and visual inspection of the modules shows delamination on CIGS27 after one year of data collection. Finally, the micromorph modules' monthly rated power varies by $5-10 \%$ month-to-month at both sites, with a clear pattern of higher power production in the summer and fall months for all modules. This seasonal variation, which has also been reported in other literature including [1,2], indicates a need to calculate energy ratings and temperature coefficients over monthly or seasonal time periods, rather than on an annual basis, for these modules. 


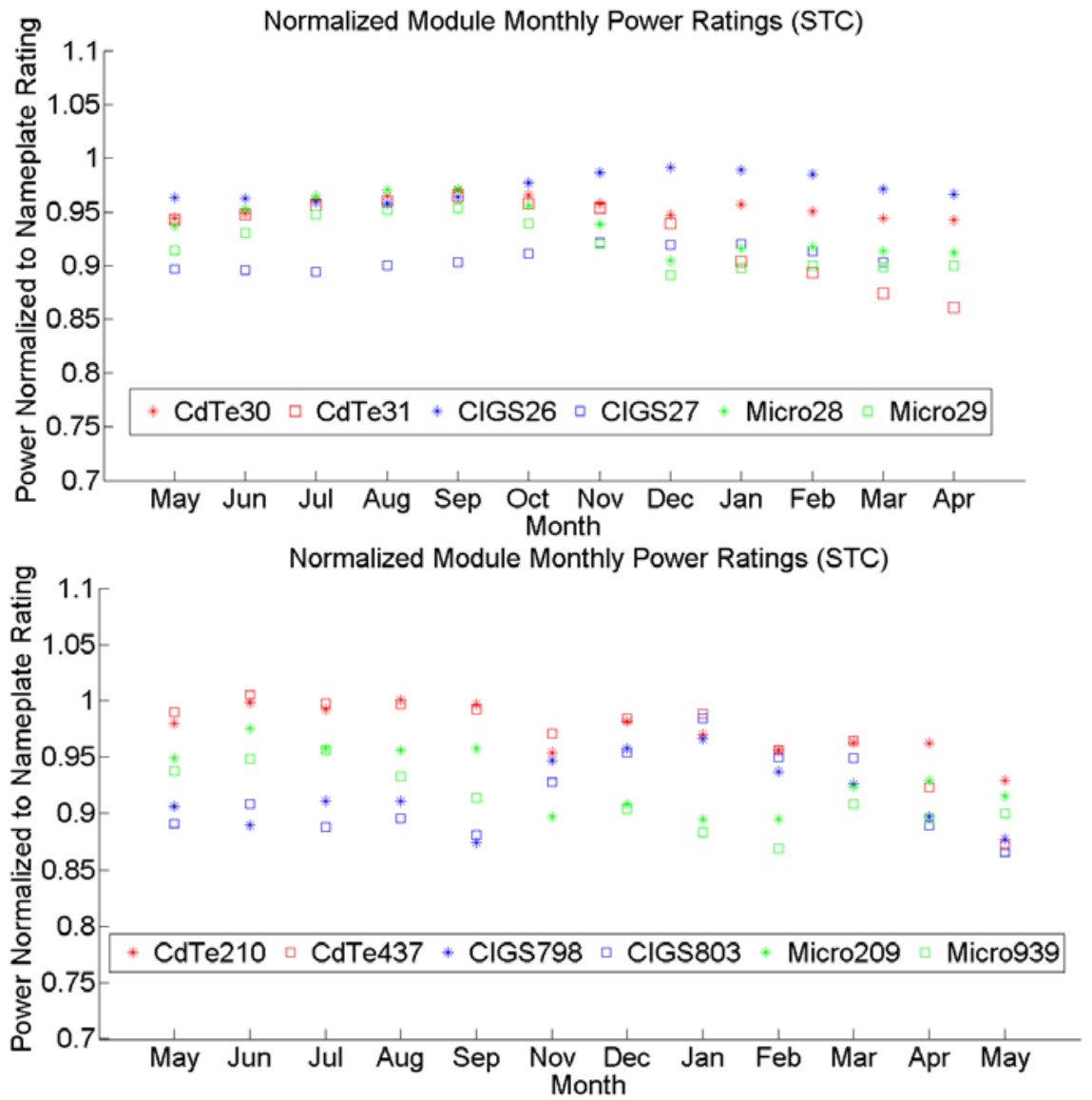

Figure 2. Thin film modules' monthly calculated STC power ratings, normalized to nameplate values, at NREL (top) and NISE (bottom); the majority of modules underperform by $5 \%$ or more at NREL, but closer to their STC ratings at NISE.

In Figure 2, it appears that May is a typical month for performance for each of the modules. Therefore, we compare the calculated STC power rating for May of 2014 (5 months after the modules were deployed in the field) to those found on each module's datasheet, as well as the STC power recorded pre-deployment (after preconditioning) for each module, indoors and outdoors (see Table 2). Interestingly, most deployed modules at NISE slightly overperform their pre-deployment power measurements, while the opposite is true for the modules at NREL; this could be due to differences in equipment or methodologies between the two sites, such as simulator spectrum, corrections, or calibration. 
Table 2. Thin Film Module Performance and Temperature Coefficients at STC

\begin{tabular}{cccc|c} 
& \multicolumn{3}{c|}{ STC power (W) } & $\begin{array}{c}\text { Datasheet Pmax } \\
\text { Temperature Coefficient }\end{array}$ \\
\cline { 2 - 5 } & Datasheet $\begin{array}{c}\text { Pre-Deployment } \\
\text { Oct. (2013) }\end{array}$ & $\begin{array}{c}\text { Outdoor } \\
\text { May (2014) }\end{array}$ & $(\% /$ deg C) \\
\hline CIGS 26 & & $121-125$ & 120.4 & \\
CIGS 27 & 125 & $116-121$ & 112.1 & $-0.34 \%$ \\
CIGS 798 & & $115-120$ & 113.3 & \\
CIGS 803 & & $114-122$ & 111.4 & \\
\hline CdTe 30 & & $84-89$ & 75.6 & \\
CdTe 31 & 80 & $85-89$ & 75.5 & $-0.25 \%$ \\
CdTe 210 & & $62-76$ & 78.4 & \\
CdTe 437 & & $65-79$ & 79.2 & \\
\hline Micro 28 & 125 & $132-146$ & 117.1 & $-0.24 \%$ \\
Micro 29 & 130 & $133-149$ & 118.9 & \\
Micro 209 & 130 & $117-122$ & 123.4 & \\
Micro 939 & 125 & $112-116$ & 117.2 &
\end{tabular}

Outdoor measurements in 2014 indicate that the micromorph modules are underperforming their datasheet STC power rating by 6-9\% at NREL, and by 5-6\% at NISE. CdTe modules at NREL also underperform by $5-6 \%$, while at NISE they are very close to their datasheet values. The CIGS modules at both sites underperform by 4-11\%. Many of these numbers fall outside of the datasheets' specified binning bounds (which allow modules to underperform by $2-5 \%$ ), but most are within the standard " $90 \%$ performance at 10 years" warranty tolerances. The observed STC performance of each module could be determined with better accuracy by using observed, rather than datasheet, performance temperature coefficients; this may be an area for future investigation.

\section{NREL Seasonal Fill Factors}

It is also useful to examine the seasonal fill factors of the three different thin film technologies as they vary with temperature and available irradiance. The NREL data are ideal for this type of investigation, as they are taken continuously with a plentiful supply of both high and low irradiance data; a similar investigation may be appropriate later at NISE once more seasonal data are collected. In this section, high irradiance data are those recorded around $1000 \mathrm{~W} / \mathrm{m}^{2}$, and low irradiance data are recorded around 500 $\mathrm{W} / \mathrm{m}^{2}$, both $+/-5 \%$. "Summer" months are June-September, while "winter" months are December-March.

Figure 3 shows the fill factor for the NREL CdTe modules. One can see that they exhibit a higher fill factor both with lower temperature and with lower irradiance, with variance of approximately $2 \%$ attributed to each. The fill factor difference with irradiance for the CdTe modules is driven by voltage; the ratio of maximum power point voltage to open circuit voltage decreases with irradiance for these particular modules. This effect has been previously observed in the field for other CdTe modules and is attributed to series resistance [5]. In contrast, the CIGS modules (Figure 4) have a higher fill factor under high irradiance operating conditions, and also with lower temperatures. In this case, the driver is the current; the ratio of maximum power point current to short circuit current is higher under the high irradiance conditions, implying that reduction in fill factor because of shunting is more important than series resistance for these modules. 


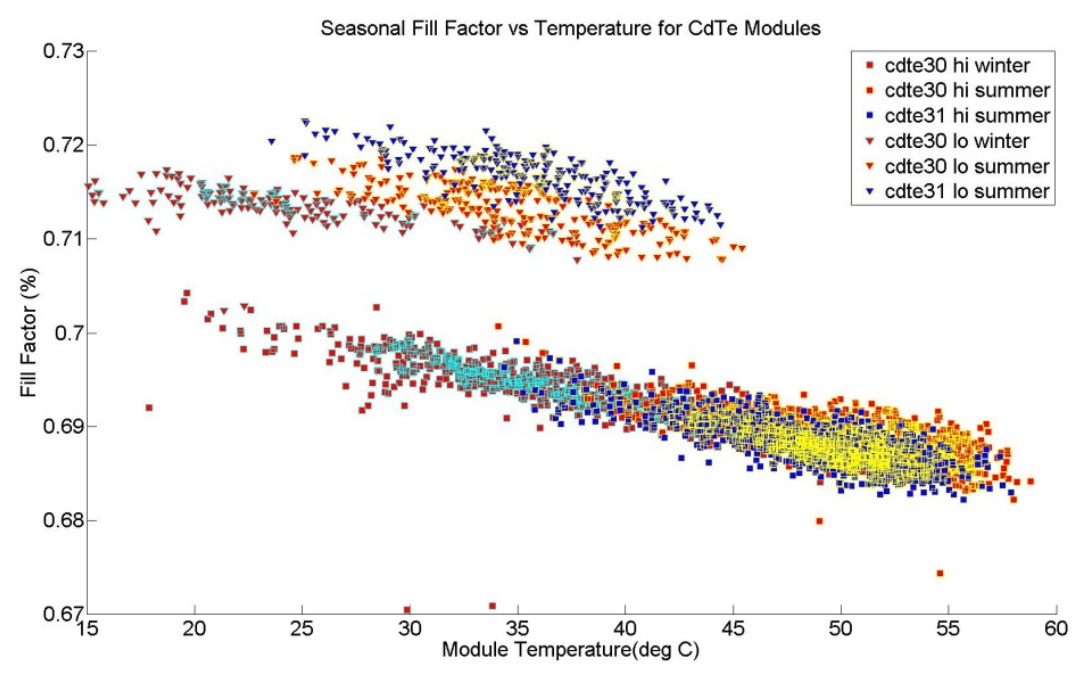

Figure 3. Seasonal fill factors at high $\left(1000 \mathrm{~W} / \mathrm{m}^{2}\right)$ and low $\left(500 \mathrm{~W} / \mathrm{m}^{2}\right)$ light levels for NREL CdTe modules, showing the effects of season, light, and temperature on their performance. Winter data from cdte31 are excluded due to previously mentioned module cracking.

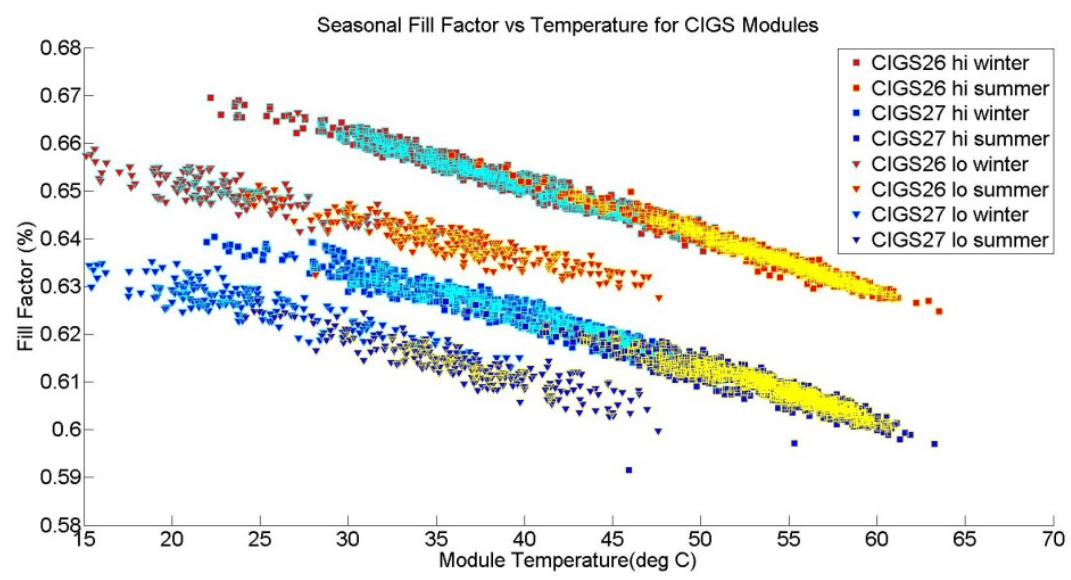

Figure 4. Seasonal fill factors at high $\left(1000 \mathrm{~W} / \mathrm{m}^{2}\right)$ and low $\left(500 \mathrm{~W} / \mathrm{m}^{2}\right)$ light levels for NREL CIGS modules, showing the effects of season, light, and temperature on their performance.

Finally, the micromorph modules' fill factors (Figure 5) increase by $2-3 \%$ in the summer months, which is attributed mostly to an increase in the ratio of maximum power point current to short circuit current during these months, a commonly-seen result of thermal annealing in amorphous silicon modules [2], as well as potential spectral effects [1]. Micromorph fill factors increase by a similar amount with lower temperatures and lower light. When the size of the metastability is similar to the size of the effect of temperature (as in this case), the concept of a temperature coefficient becomes poorly defined. Lightinduced degradation and annealing to reverse the degradation have been well studied and complicate the analysis of performance of micromorph cells as a function of location, especially because the details of the degradation and recovery depend on the structure of the cells. 


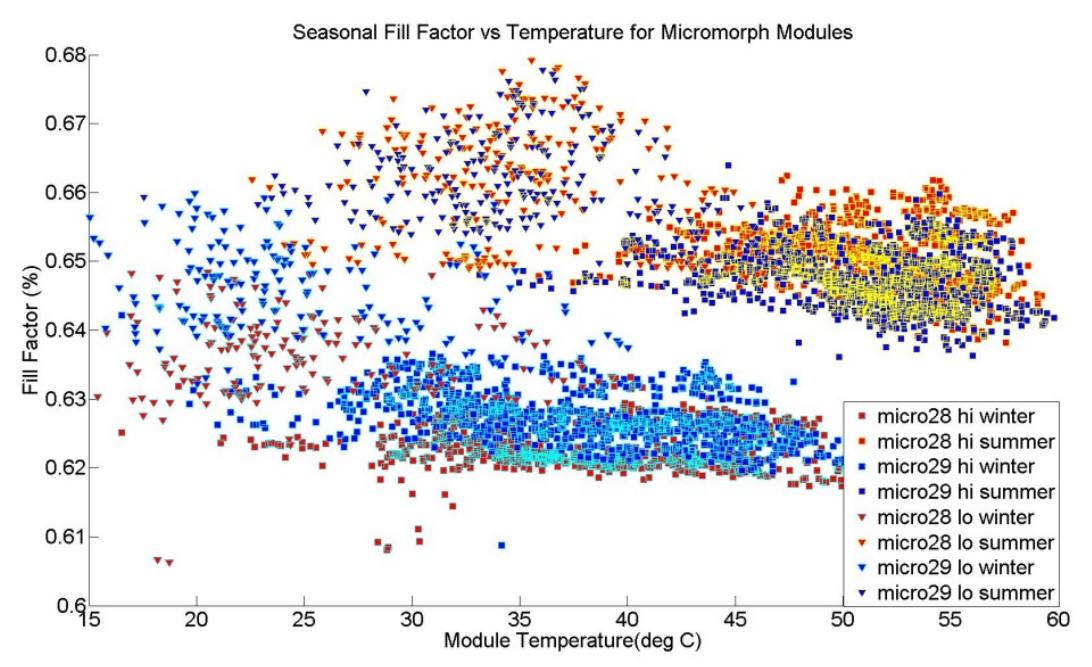

Figure 5. Seasonal fill factors at high $\left(1000 \mathrm{~W} / \mathrm{m}^{2}\right)$ and low $\left(500 \mathrm{~W} / \mathrm{m}^{2}\right)$ light levels for NREL Micromorph modules, showing the effects of season, light, and temperature on their performance.

\section{Energy Production}

Energy production is analyzed by examining monthly performance ratios [6] for each module at both the NREL and NISE sites. The performance ratio is a dimensionless term that indicates a PV system's production, normalized to both system size and available radiation over a period of time. In the equation below, $\mathrm{E}$ is the total system (or module) energy output over a given time interval, $\mathrm{G}$ is the reference irradiance $\left(1000 \mathrm{~W} / \mathrm{m}^{2}\right), \mathrm{P}_{0}$ is the system's reference output under STC, and $\mathrm{H}$ is the total available insolation over the time interval to be considered.

$$
P R=\frac{E * G}{P_{0} * H}
$$

Performance ratios for PV are typically calculated from continuously recorded performance data, which at the time of this report are not yet available from NISE. It is important to note here that the intermittent recording of data at NISE for each technology from 2014-2015 may bias the performance ratio results.

The ratios are first calculated using the modules' nameplate ratings for STC power (Figure 6). In an initial evaluation of the NREL modules, one can see that the CdTe modules perform similarly until October, then in November they diverge. This is an anomaly-CdTe 30 had snow on it for 2 extra days as compared to CdTe31 according to the performance data. The effects of the crack on CdTe31 apparently begin to appear in late December. The CIGS modules have a $\sim 7-8 \%$ difference in performance ratio from one another for all months. This is most likely a nameplate issue; as noted in Table 2, CIGS27 underperforms significantly. Using the datasheet nameplate ratings for calculation of performance ratios reflects the consistency of the module manufacturing process, which is desirable in some scenarios, but may make it more difficult to directly compare performance on the basis of technology alone.

Monthly performance ratios at NISE show the CdTe modules initially slightly outperform the other technologies, relative to their nameplate values. As at NREL, the NISE CIGS modules perform relatively worse in the summer and better in the winter months, while the micromorph modules show the opposite seasonal behavior. Each technology's module pair at NISE appears to be well matched in performance relative to their datasheet nameplate ratings. Overall the performance ratios are slightly higher at NISE than NREL, relative to nameplate ratings. This may be due to differences in data collection methodologies. For example, at NISE measurements were taken on a manual two-axis tracker on which measurements 
are exclusively taken at normal incidence, and NISE uses a silicon reference cell for irradiance measurements, which could give slightly different results relative to the thermopile pyranometer employed at NREL. Another important difference is the continuous data collection at NREL versus intermittent measurement at NISE.
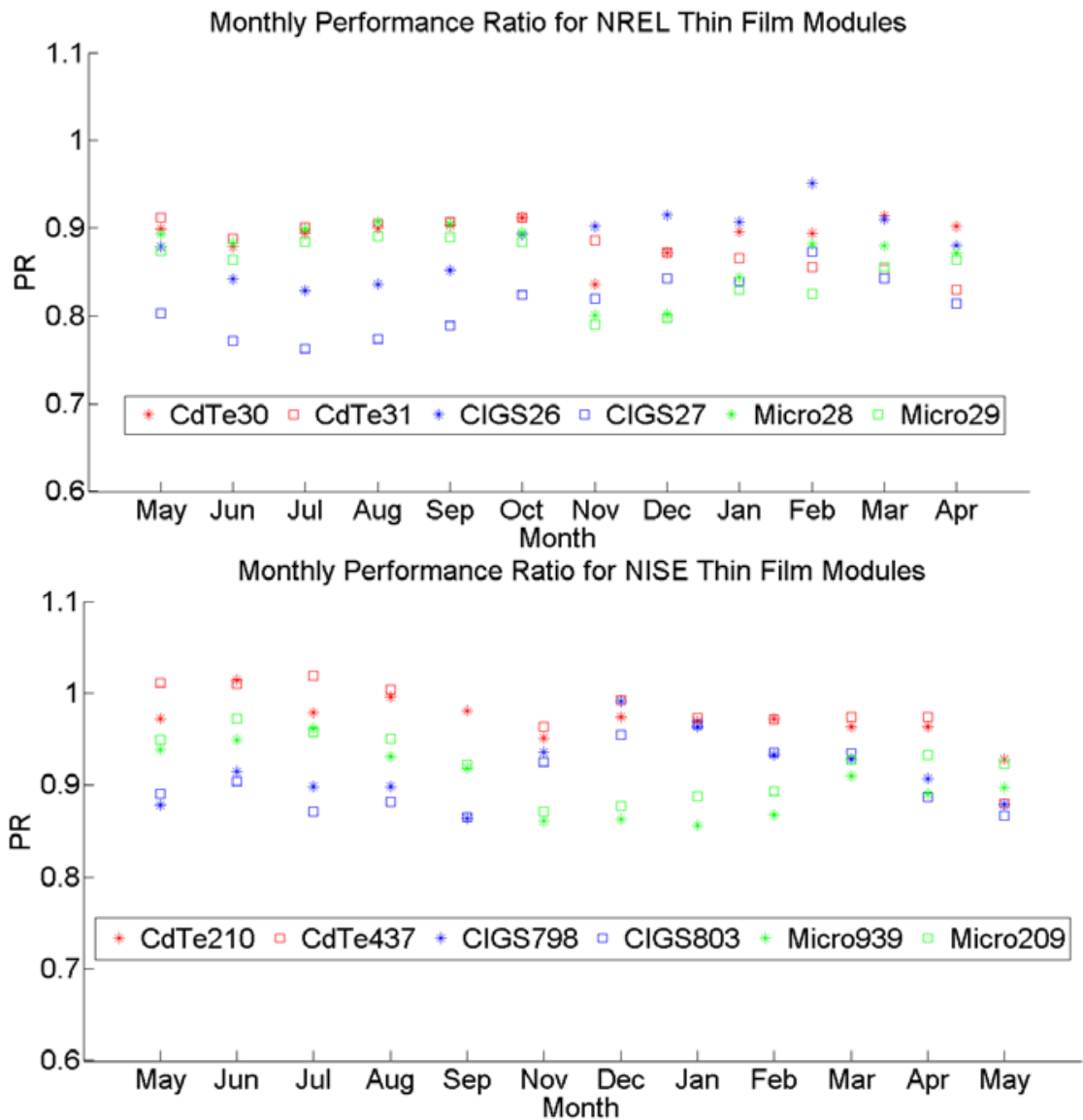

Figure 6. Monthly performance ratios for thin film modules at NREL (top) and NISE (bottom) calculated using module nameplate ratings.

Figure 7 shows the results when the performance ratios are calculated using each module's individual observed STC power from May, 2014 (Table 2). Though performance ratios for PV systems are usually $<1$, these are ratios for DC energy for single modules - the ratios do not include inverter losses or other losses commonly seen at the PV system level (mismatch, etc.), where performance ratios are often calculated. One can see that modules of each technology now have similar performance ratios to one another both at NREL and NISE. Use of the observed STC power in performance ratio calculation better reflects the performance of the technology, making it more straightforward to compare multiple products. 


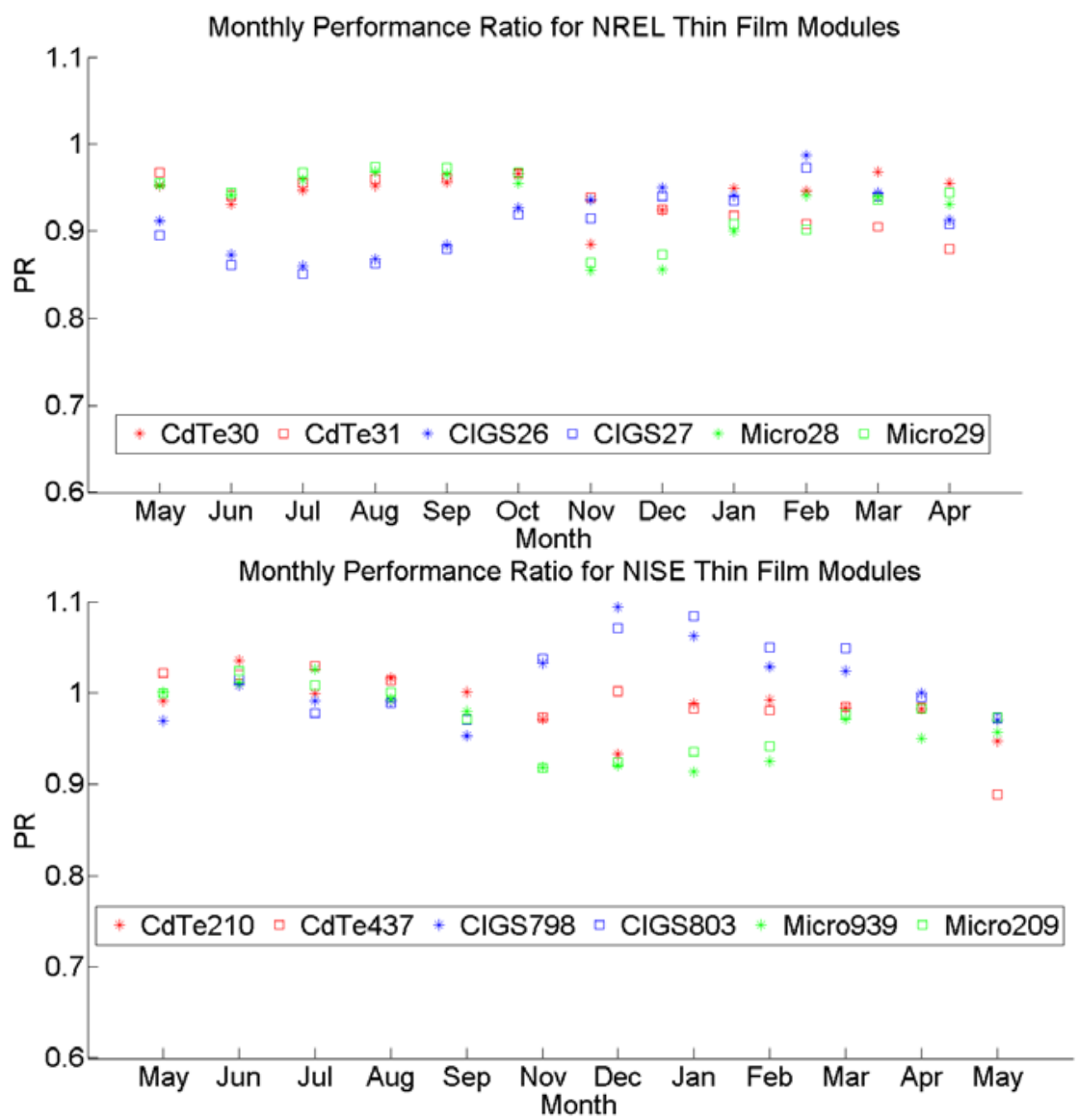

Figure 7. Monthly performance ratios for thin film modules calculated using observed STC module performance at NREL (top) and NISE (bottom); the three technologies show different site-specific performance ratio trends relative to one another.

Generally speaking, one expects to see performance ratios that are higher in the winter than in the summer, accounting for temperature effects [6]. This is the case for the CIGS modules at both sites. However, at NREL and NISE, we see higher performance ratios in the summer for micromorph. The higher values reflect higher currents, which is likely to be a spectral effect; the spectral effect may dominate because of the relatively small performance temperature coefficient for this technology's modules. The higher summertime performance ratio for the NREL micromorph modules is also caused by their higher summertime fill factor (Figure 5); this may be the case at NISE as well. The CdTe modules have a fairly constant performance ratio at both sites, though as previously mentioned, module CdTe 31 developed a crack, and one can clearly see the effects of this damage from January-March in the drop in performance ratio for this module. Additionally there are several days with wintertime snow on the NREL modules (November-March), which accounts for their slightly lower relative performance during these months.

Figure 7 also shows some interesting site-specific differences in the thin film technologies' performance ratios relative to one another, even though each site's annual patterns for the individual technologies are similar. At NREL, the CIGS modules have a much lower summertime performance ratio relative to the other technologies, while at NISE the summertime performance ratios of all three technologies are comparable. Then in the winter months (which are the rainy season at NISE) one sees an advantage for CIGS relative to the other technologies at NISE, while CIGS and CdTe are similar to one another at NREL. These observed effects may be attributed to different weather patterns at the two sites, but could also be partly due to the limited available data at NISE, which may or may not be representative of each month's actual operating conditions. 
Calculation of monthly performance ratios, and examination of the modules' relevant performance metrics such as fill factor, allow us to see that of the three thin film modules in this report, the CdTe module performance appears most similar between the two sites. The micromorph modules may also be more advantageous in NREL's climate than at NISE, while CIGS appears better at NISE than at NREL (based on observed performance ratio), but one would need to further examine the seasonal effects with continuous data monitoring at NISE to see if the performance ratios calculated here are truly representative of the site conditions. It is important to note that the results described here apply only to these particular modules, and that in general, differences in active material formulations within a given material system could offer different advantages and disadvantages in various climates.

\section{Summary and Future Work}

This report focuses on evaluation of the measured performance data for twelve thin film modules of three technology types (CdTe, CIGS, and Micromorph) over a period of one year, located in Golden, Colorado and Gurgaon, India. While some of the modules were found to underperform slightly compared to their datasheets' listed power ratings at STC, all but two are within warranty specifications. Their monthly performance normalized to STC power ratings varies by as much as $10 \%$ over the course of the year. This effect was further examined by looking at fill factor trends among the modules of different technologies at NREL, noting that they vary with light, temperature, and season in different ways. Of the modules in this study, we see that the CdTe modules perform consistently at both the NREL and NISE sites, while micromorph performs better during the warmer summertime months at NREL and CIGS performs better during the rainy winter months at NISE. While these limited results cannot be generalized to entire PV technologies (modules of the same technology may have different temperature coefficients and/or fill factor variance), the methods described herein are a good basis for evaluation and comparison of modules for a particular site or climate. Future work with these modules should include examination of degradation as the modules continue to be monitored over a period of years. It may also be interesting to perform further comparison of module characteristics and performance metrics, such as temperature coefficients and fill factor, with the availability of more data.

\section{References}

[1] Silverman, Timothy J., et al. Characterisation of Performance of Thin-film Photovoltaic Technologies. No. IEA-PVPS T13-02. INTERNATIONAL ENERGY AGENCY PHOTOVOLTAIC POWER SYSTEMS PROGRAMME (2014).

[2] Gottschalg, Ralph, et al. "Investigating the seasonal performance of amorphous silicon single-and multi-junction modules." Photovoltaic Energy Conversion, 2003. Proceedings of 3rd World Conference on. Vol. 2. IEEE, 2003.

[3] Marion Bill. Preliminary Investigation of Methods for Correcting for Variations in Solar Spectrum under Clear Skies. No. NREL/TP-520-47277. National Renewable Energy Laboratory (NREL), Golden, CO., 2010.

[4] Silverman, Timothy J., et al. "Outdoor performance of a thin-film gallium-arsenide photovoltaic module." Photovoltaic Specialists Conference (PVSC), 2013 IEEE 39th. IEEE, 2013.

[5] Del Cueto, J.A. "Review of the field performance of one cadmium telluride module." Progress in Photovoltaics: Research and Applications 6.6 (1998): 433-446.

[6] Marion, Bill., et al. "Performance parameters for grid-connected PV systems."Photovoltaic Specialists Conference, 2005. Conference Record of the Thirty-first IEEE. IEEE, 2005. 